\title{
Attribution Bias and Event-Related Potential using a Real-time Based Attribution Experiment (the Colour Test)
}

\author{
$\mathrm{Su}$ Young Lee \\ Department of Medicine \\ The Graduate School, Yonsei University
}




\section{Attribution Bias and Event-Related Potential using a Real-time Based Attribution Experiment (the Colour Test)}

Directed by Professor Suk Kyoon An

The Doctoral Dissertation submitted to the Department of Medicine, the Graduate School of Yonsei University in partial fulfillment of the requirements for the degree of Doctor of Philosophy

Su Young Lee

June 2011 


\title{
This certifies that the Doctoral Dissertation of $\mathrm{Su}$ Young Lee is approved.
}

\author{
Thesis Supervisor: Suk Kyoon An
}

Dong Goo Kim : Thesis Committee Member \#1

Myongsei Sohn: Thesis Committee Member \#2

Kee Namkoong: Thesis Committee Member \#3

Ji-Woong Kim: Thesis Committee Member \#4

\section{The Graduate School Yonsei University}

June 2011 


\section{ACKNOWLEDGEMENTS}

I would like to express my deep gratitude to people around me who make it possible to write this doctoral thesis.

First of all, this thesis would not have been possible without the support and patience of my thesis supervisor, Professor Suk Kyoon An. He was the one who taught me how to research from basic to advance. The kind support of Professor Kee Namkoong has been inspired me with my enthusiasm. I am also grateful to Professor Dong Goo Kim for his careful and sincere comments, to Professor Myongsei Sohn for his suggestions which enriched discussion, and to Professor Ji-Woong Kim for his thoughtful comments for the experimental design.

I would also like to thank researchers in Section of Affect and Neuroscience who lend me their hands in carrying out this study. Lastly, I really appreciate my family, they have always encouraged me in my way. 


\section{TABLE OF CONTENTS}

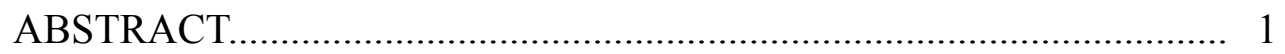

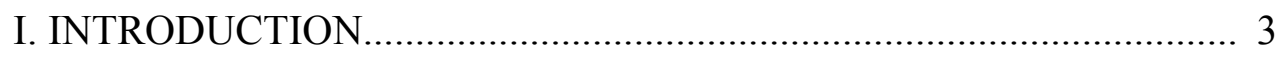

II. METHODS

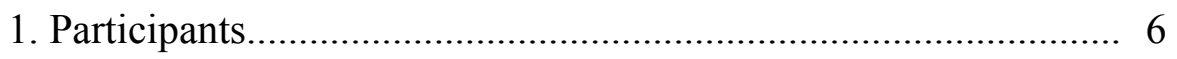

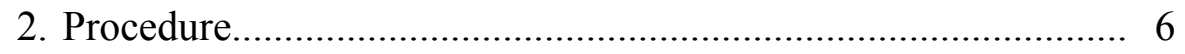

3. Stimuli and experimental design................................................. 7

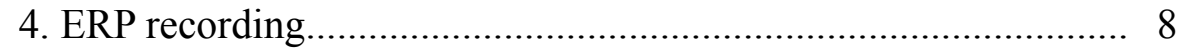

5. Analyses of ERP data............................................................ 9

III. RESULTS

1. Behavioral data................................................................... 10

2. ERP findings.................................................................... 11

IV. DISCUSSION

1. Extract neural correlates of attribution......................................... 16

2. Comparison of extracted neural correlates by type of attribution. 17

3. Comparison of extracted neural correlates by type of event........ 18

4. Limitations............................................................................... 19

V. CONCLUSION

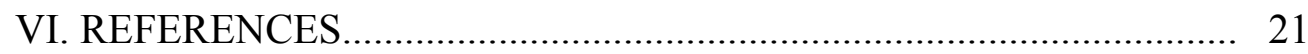

ABSTRACT (IN KOREAN) .......................................................... 24

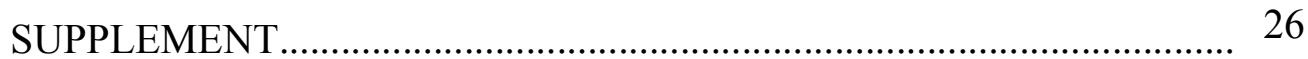




\section{LIST OF FIGURES}

Figure 1. Example trial for the 'Colour test'............................... 8

Figure 2. ERP waveforms, averaged across all subjects for all six attribution conditions............................................ 10

Figure 3. Grand-averaged ERP waveforms at midline channels for self, other, situation attribution trials and control trials in the positive (win) and negative (loss) events.

\section{LIST OF TABLES}

Table 1. Results for the ANOVAs on the attribution, frontality and laterality.....

Table 2. Comparison of neural activities of extracted neural correlates by type of attribution. 


\title{
ABSTRACT \\ Attribution bias and event-related potential using a real-time based attribution experiment (the colour test)
}

\author{
Su Young Lee \\ Department of Medicine \\ The Graduate School, Yonsei University \\ (Directed by Professor Suk Kyoon An)
}

Attribution is a notable social cognition that underlies major psychopathologies such as depression and persecutory delusion. The purpose of present study was to investigate neural correlates of self, other, and situation attribution respectively, and to find out the neural base of selfserving bias through comparisons of extracted neural correlates of each attribution. The colour test was developed as a real-time based attribution experiment that could realize three types of attribution. Twenty healthy subjects informed that they would enter a color matching game with other two players who were connected online. Participants were asked to attribute the cause of win or loss to self, others or situation during event-related potentials (ERPs) were recorded. As a result, the fronto-central late positive complex (LPC) was extracted as a neural correlate of attribution. LPC amplitudes for the other-attribution were higher than LPCs for the selfattribution, and it suggested that other-attribution might demand more cognitive loads than self-attribution. LPC amplitudes of self-attribution for negative events were higher than those for positive events, and it suggested that the self-attribution might play a pivotal role in the self-serving bias. Applying this real-time based paradigm (colour test) to clinical population such as depression or paranoia patients would provide further insights for 
role of attribution in human psychopathologies.

Key Words: Attribution, Self-serving bias, Colour test, Event-Related Potential, Social cognition 


\title{
Attribution bias and event-related potential using a real-time based attribution experiment (the colour test)
}

\author{
$\mathrm{Su}$ Young Lee \\ Department of Medicine \\ The Graduate School, Yonsei University \\ (Directed by Professor Suk Kyoon An)
}

\section{INTRODUCTION}

Social cognition refers a set of mental operation which process information about self and others in social interactions ${ }^{1}$. Effective social functioning is an essential for one's survival. Evidences are growing that the maladaptive social functioning, rather than symptom severities, was related to the disability and the prognosis of major psychiatric illnesses ${ }^{2,3}$. Recently, researches to find out social cognitive functions which are related to major psychopathologies have expanded ${ }^{4,5}$. Attribution style is one of notable social cognition that underlies psychological theories explaining the mechanism of depression and persecutory delusion ${ }^{5-8}$.

Attribution is a cognitive process to make a causal inference about personally significant events ${ }^{9}$. Attribution could be largely categorized into 'internal' (assigning a cause to self) and 'external' attribution (assigning a cause to environment or someone other). There are some attribution styles which suggested as important cognitive processes in human psychopathologies - the self-serving bias and the personalizing bias ${ }^{10}$. The self-serving bias means the tendency of the internal attribution for positive events (self-enhancing bias) and the external attribution for negative events (self-protective bias) ${ }^{11}$. This bias considered as a natural coping mechanism which helped people to enhance and maintain their self- 
esteem. Decreased use of self-serving bias was suggested as a social cognitive process of depression, and greater self-serving suggested as a process of paranoia ${ }^{8}$ 10,11. External attributions for negative events could be divided into the attribution to others and the attribution to situations. The tendency of more attribution to others than to situations for negative events called as a personalizing bias, and this bias was an important attribution style which explains developing paranoia ${ }^{12,}{ }^{13}$. Psychological researches on attribution styles using questionnaires have developed above theoretical frameworks $9,14,15$, however, the researches for neural underpinning of attribution have just begun.

Blackwood et al. ${ }^{16}$ investigated the neural correlates of each attribution style using fMRI imaging during attributional decision tasks. The self-serving attribution was related to regions previously implicated in motivated behavior, and the nonself-serving attributions were associated with activations in the left lateral orbitofrontal cortex, right angular gyrus, and right middle temporal gyrus. This study firstly demonstrated neural correlates of attribution, but had limitation that it relied upon a mental simulation. Since attribution is a cognitive process about personally significant events, real-time experimental events which are positive or negative for participants themselves would be more ideal. Krusemark et al. ${ }^{17}$ designed a real-time experimental attribution task with a bogus success or failure feedback about participants' performance. Neural correlates of attribution were investigated by voltage and source analyses for EEG records, and as a result, nonself-serving attributions were preceded by enhanced dorsomedial frontal cortex activity at the $320 \mathrm{~ms}$ time point compared to self-serving responses. However, prior experiments have failed to examine other-attribution and situation-attribution respectively, and investigated neural correlates for attribution using composite variables (i.e. self-serving attribution was a summation of self-attribution for positive event, other/situation-attribution for negative event). However, as Bentall has noted ${ }^{18}$, the self-attribution for positive event and the other/situation-attribution for negative event might have different mechanisms even if they both classified into 'self-serving' attribution. Therefore, the collapsing analysis method might not be appropriate, rather, a neural bases of each attribution need to be examined separately. 
The purpose of present study was to extract neural correlates of each attribution separately and to investigate neural base of self-serving bias through event-related potentials of electroencephalography (EEG) using a real-time based attribution experiment. To realize this, a novel attribution task ('a colour task') which could examine three types of attribution was developed. First, we tried to extract neural correlates of respective attribution (attribution to self, other and situation for the positive and the negative event) through comparison with control trials (color recognition). We expected that there would be common neural responses which showed higher amplitudes in attribution trials than in control trials across types of attribution. Considering prior findings, event-related potentials for attribution needed to be explored to the later time window because significant difference between attribution conditions were observed in the prefrontal region in both ERP and fMRI studies ${ }^{16,17}$. Frontal late positive potentials (800-1600 ms) are known to reflect prefrontal activity with post-retrieval attribution ${ }^{19-21}$ whereas parietal P300s mainly reflect attention or memory encoding. Post-retrieval memory processing involved with the attribution of the source of memory ${ }^{19}$, other item specific features ${ }^{19}$ or with the specific attribution of test cue compared with information retrieved from memory ${ }^{21}$. Therefore, it might be in line with attribution of the cause of event in this study. We expected that frontal late positive potentials or parietal P300s would be extracted as a possible component of causal attribution. Second, we investigated neural base of self-serving bias through comparison of neural activities of extracted neural correlates by type of attribution (compare amplitudes of self-other-situation attributions in one event) and by type of event (compare amplitudes of positive-negative events in one attribution). We expected that attribution types which contribute to non-self-serving bias (self-attribution for negative event, other/situation-attribution for positive event) would show higher neural activities than attribution types which contribute to self-serving bias (selfattribution for positive event, other/situation-attribution for negative event) because of higher burden of cognitive processing. 


\section{MATERIALS AND METHODS}

\section{Participants}

Twenty healthy volunteers (10 male, 10 female) were recruited through an internet advertisement. The mean age was 23.5 years old (age range 19-30). Participants with current or past psychiatric illness, neurological illness or traumatic brain injury were excluded through an interview. After a complete description of the study was provided to the participants, written informed consent was obtained. Our study was carried out under the guidelines for the use of human subjects established by the Institutional Review Board at Severance Mental Health Hospital, Yonsei University.

\section{Procedure}

A real-time attribution task, named 'Colour test', was developed (Figure 1). Participants were informed that they would enter a color matching game with other two players who were connected online. If more than two of all three players got the correct answer, all would win the money (5000 Korean won, about 4 dollar 50 cents in US dollars), but if more than two were wrong, all would lose the money (5000 Korean won). The final game money would be actually paid in addition to their basic reward for participation to make real-time, self-relevant positive and negative events. The other two players were counterfeit, and all trials were presented in a fixed pseudorandom order to maintain an equivalent positive and negative event condition in every participant. To enhance the reliability of online game setting, a session was started with a bogus online access sound and sign. A total of 280 trials (140 positive events, 140 negative events) were presented via STIM2 software program (Compumedics, Charlotte, NC, USA). Total duration of the task was 47 minutes, it was divided into three sessions to reduce participants' fatigue.

After developing above colour test, a pilot study was done with 8 college students who were not part of the present study. They confirmed that this task was ambiguous whether they get the right answer or not and was believable that three people were participating.

In the actual experiment, participants performed practice sessions until he felt 
to be familiar with the task, after that the participant entered into the EEG room and started the real session. After completing the task, participant debriefed about 1) how much did he think that he got the correct answer (graduated on the correctness scale : w-WAS scale) 2) did he keep in mind that three people were participating 3) did he have any other doubts about this experiment. One participant debriefed that he was doubtful that this experiment was a fake because he thought that the size of the program file was too small to be an online game (His major in college was a computer science), so his data were excluded from the analysis. To validate the construct of colour test, an Attribution and Self-Consciousness Questionnaire $(\mathrm{ASCQ})^{22}$ were also assessed.

\section{Stimuli and experimental design}

The time and stimulus details are demonstrated in Figure 1. Each trial consisted of a fixation cross, a target color, two distractors (gray scale colours), and a probe. The probe consisted of two colors that have increased and decreased chroma in a same degree from the target color on the color spectrum $(R+5, G+5$, B +5 and R-5, G-5, B-5). Therefore, participants should select between two colors which were very similar but not exactly same with the target color. We expected that attribution biases would reveal better under this forced-choice condition which participants' own correctness was ambiguous. After showing bogus results of win or loss and the game money, subjects were asked to attribute the cause of the result to 'self', 'other player', or 'level of task difficulty or an accident' (self-other-situation).

The control trial was same with experimental trials except the final attribution was substituted with very simple color recognition question (select the target color among 'target color' - 'white' - 'black'). Total of 280 trials consisted of 240 attribution trials and 40 control trials. Participants were instructed to choice the right color and then to attribute the game result as fast as possible using " 1 ", "2", " 3 " response buttons on the game keypad. The order of attribution buttons were counterbalanced across the participants. 


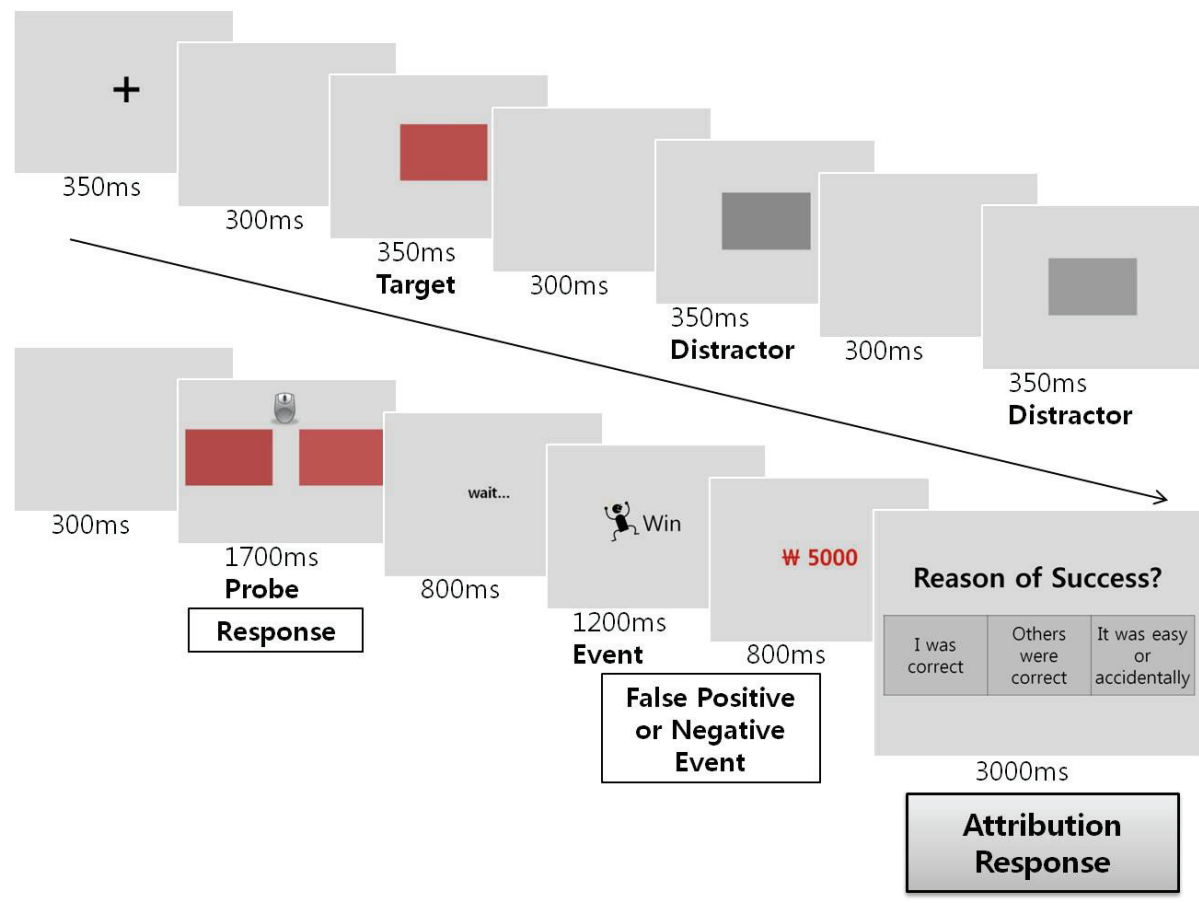

Figure 1. Example trial for the 'Colour test'. Following a target color and two gray-scale distracters, participants were asked to choice one color between two probe colors. After that, a bogus win or loss feedback (positive and negative event) was provided, and participants were asked to attribute the event to self, other or a situation. ERPs were averaged between from $100 \mathrm{~ms}$ before the attribution response and $1300 \mathrm{~ms}$ after the response.

\section{ERP recording}

Electroencephalogram (EEG) activity was recorded from a 64-channel $\mathrm{AgCl}$ lead cap according to the international $10 / 20$ system with a $0.05-100 \mathrm{~Hz}$ analogue bandpass and a sampling rate of 1,000 Hz/channel (SynAmps, Compumedics Neuroscan, Charlotte, NC, USA). The recordings were referenced to linked electrodes placed on both mastoid processes. Eye blinks and movements were monitored by electrodes placed near the outer canthus and beneath the left eye. The electrode impedance was maintained at $10 \mathrm{k} \Omega$ or below. The EEG was amplified using a band-pass filter between $0.15 \mathrm{~Hz}$ (6 dB/octave roll-off) and $40 \mathrm{~Hz}$ (36 $\mathrm{dB} /$ octave roll-off). Trials were adjusted by regression from electrooculograms to control for ocular movement artifacts. Artifacts were rejected if the F1, F2, FP1, 
FP7 potential amplitudes exceeded $\pm 50 \mu \mathrm{V}$. The low-pass filter was set to $8.5 \mathrm{~Hz}$ (24 dB/octave roll-off, zero phase order) to control for muscular movement and alpha-wave activity. After rejecting artifacts, remaining trials of all subjects in the target condition ranged from 27 to 34. ERPs were averaged between prestimulus $100 \mathrm{~ms}$ and poststimulus $1300 \mathrm{~ms}$.

We included all cases with more than 15 responses in each attribution to overview the neural correlates of each attribution. Therefore, the number of subjects who entered into the analysis was different from each attribution condition (win-self $(\mathrm{n}=17)$, win-other $(\mathrm{n}=15)$, win-situation $(\mathrm{n}=12)$, loss-self $(\mathrm{n}=19)$, loss-other $(\mathrm{n}=17)$, loss-situation $(\mathrm{n}=10)$ ). Because this colour test had a control condition (win-control $(n=19)$, loss-control $(n=19))$, ERP components of each attribution could be examined respectively with those of the control. Previous studies had limitations that neural correlates of attribution were examined only through composite variables due to the paucity of specific responses (e.g. other-attribution and situation-attribution were collapsed into an 'external-attribution').

\section{Analyses of ERP data}

The waveform of grand average of all subjects and all attribution conditions which had more than 15 responses is demonstrated in figure 2. Three peaks were observed with the latency of about $140 \mathrm{~ms}, 290 \mathrm{~ms}$ and $360 \mathrm{~ms}$. The maximal amplitude of P140 and N290 were shown at the fronto-central site, so considered as frontal P2 and N2 components, and the P360 was maximal at the parietal site, and decreased in central and frontal areas, so considered as a parietal P3 component. After the P3 peak, a late positive complex (LPC) was observed with the peak latency about $770 \mathrm{~ms}$ at the $\mathrm{Cz}$ electrode site. To quantify the late positive complex (LPC), the waveform between $600 \mathrm{~ms}-1100 \mathrm{~ms}$ analyzed in every $100 \mathrm{~ms}$ series of time window (Figure 2). 


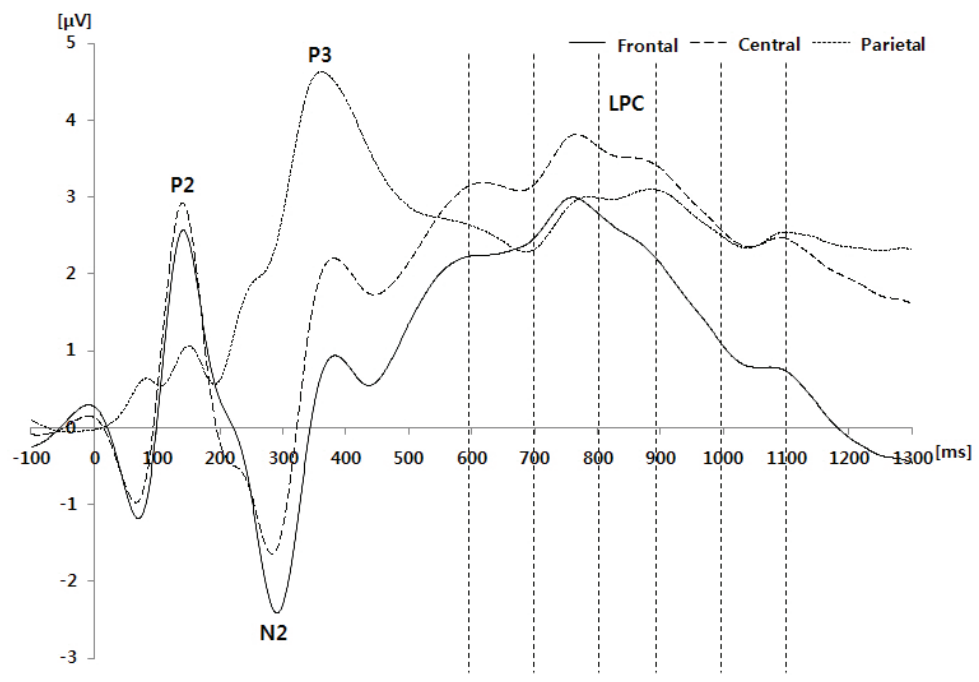

Figure 2. ERP waveforms, averaged across all subjects for all six attribution conditions.

Three peaks (P2, N2, P3) and one late slow wave (LPC) was observed. Solid line: frontal sites ; dashed line: central sites; dotted line : parietal sites.

First, to extract the neural correlate of attribution, mean amplitudes and latencies of P2, N2, P3 and mean amplitudes of LPC in every $100 \mathrm{~ms}$ time window between attribution and control trials were compared by repeated measures of analysis of variance. Second, extracted neural correlates of the attribution were compared each other by type of attribution (compare amplitudes of self-othersituation attributions in one event) and by type of event (compare amplitudes of positive-negative events in one attribution) using Wilcoxon signed-rank tests.

\section{RESULTS}

\section{Behavioral data}

An event (win, loss) $\mathrm{x}$ attribution (self, other, situation) repeated measures of analysis of variance (ANOVA) revealed significant attribution effect $(F(2,17)=10.7$, $\mathrm{p}<0.001)$, but no interaction effect $(\mathrm{F}(2,17)=0.1, \mathrm{p}=0.943)$. The response rates for self-attribution were highest regardless of events, and followed by other-attributions and situation-attributions (mean (SD): win event - self: 47.2 (26.9) \%; other: 31.8 (23.6) \%; situation: 21.0 (16.2) \%, Loss event - self: 49.2 (19.2) \%; other: 30.2 
(15.7) \%; situation: 20.6 (15.0) \%). Self-attribution rates between the positive event and the negative event were not significantly different $(\mathrm{p}=0.774)$, and this result meant that the self-serving bias was not shown in this participant group. To validate the construct of colour task, Spearman's rank correlation analyses between scores of Attribution and Self-Consciousness Questionnaire (ASCQ) which were assessed in these participants and the attribution rates of colour test were done. Otherattribution rate for negative (loss) events of colour test was positively correlated with the other's intention score for ambiguous events $(\rho=0.583, p=0.009)$ and the self-reference score for good events of ASCQ $(\rho=0.486, p=0.035)$. Self-attribution rate for negative events (loss) of colour test was negatively correlated with the other's intention score for ambiguous events $(\rho=-0.497, p=0.030)$ and the selfreference score for good events of ASCQ $(\rho=-0.474, p=0.041)$. Because ambiguous events of ASCQ are somewhat negative (e.g. Someone goes out of a room during your speech.), the attribution style between the ASCQ and the colour test could be considered as consistent.

\section{ERP findings}

Results of ANOVAs are presented in table 1 and figure 3 with grand averaged ERP waveforms. LPC time windows showed significant attribution effects or significant interactions of attribution with frontality or laterality. For the selfattribution in the positive event, significant attribution $\mathrm{x}$ laterality interaction in time windows of 600-800 ms revealed significant attribution effect in the central sites. (LPC 600-700: $\mathrm{F}_{(1,16)}=5.67, \mathrm{p}=0.030$; LPC 700-800: $\mathrm{F}_{(1,16)}=5.88, \mathrm{p}=0.028$ ). For the other-attribution in the positive event, attribution $\mathrm{x}$ frontality effect in 600-800 ms revealed significant attribution effects in frontal (frontal LPC 600-700: $\mathrm{F}_{(1,14)}=24.78$, $\mathrm{p}<0.001$; LPC 700-800: $\mathrm{F}_{(1,14)}=18.52, \mathrm{p}=0.001$ ) and in central regions (LPC 600-700: $\mathrm{F}_{(1,14)}=21.76, \mathrm{p}<0.001 ;$ LPC 700-800: $\left.\mathrm{F}_{(1,14)}=31.00, \mathrm{p}<0.001\right)$, and attribution $\mathrm{x}$ laterality effect in $800-900 \mathrm{~ms}$ revealed significant attribution effects in central $\left(\mathrm{F}_{(1,14)}=15.15, \mathrm{p}=0.002\right)$ and in right sites $\left(\mathrm{F}_{(1,14)}=14.22, \mathrm{p}=0.002\right)$. For the self- 
attribution in the negative event, significant attribution $\mathrm{x}$ frontality effect in time windows of 600-900 ms revealed significant attribution effects in frontal (LPC 600700: $\mathrm{F}_{(1,18)}=7.14, \mathrm{p}=0.016 ;$ LPC 700-800: $\mathrm{F}_{(1,18)}=8.97, \mathrm{p}=0.008 ;$ LPC 800-900: $\left.\mathrm{F}_{(1,18)}=7.29, \mathrm{p}=0.014\right)$ and in central regions (LPC 600-700: $\mathrm{F}_{(1,18)}=11.44, \mathrm{p}=0.003$; LPC 700-800: $\mathrm{F}_{(1,18)}=10.74, \mathrm{p}=0.004$; LPC 800-900: $\left.\mathrm{F}_{(1,18)}=7.37, \mathrm{p}=0.014\right)$, and attribution $\mathrm{x}$ laterality effect in 600-900 $\mathrm{ms}$ revealed significant attribution effects in central (LPC 600-700: $\mathrm{F}_{(1,18)}=12.39, \mathrm{p}=0.002$; LPC 700-800: $\mathrm{F}_{(1,18)}=13.16, \mathrm{p}=0.002$; LPC 800-900: $\mathrm{F}_{(1,18)}=9.45, \mathrm{p}=0.007$ ) and in left sites (LPC 600-700: $\mathrm{F}_{(1,18)}=5.23$, $\mathrm{p}=0.035$; LPC 700-800: $\mathrm{F}_{(1,18)}=5.73, \mathrm{p}=0.028$; LPC 800-900: $\left.\mathrm{F}_{(1,18)}=5.59, \mathrm{p}=0.029\right)$, attribution effects in right sites were trend level of significance (LPC 600-700: $\mathrm{F}_{(1,18)}=3.35, \mathrm{p}=0.084 ;$ LPC 700-800: $\mathrm{F}_{(1,18)}=4.27, \mathrm{p}=0.053 ;$ LPC 800-900: $\mathrm{F}_{(1,18)}=3.84$, $\mathrm{p}=0.066$ ). For the other-attribution in the negative event, significant attribution $\mathrm{x}$ frontality effect in time windows of $600-800 \mathrm{~ms}$ and significant attribution $\mathrm{x}$ laterality effect in time windows of 600-1000 ms revealed significant attribution effect across all regions and sites which showed dominant significance at central sites of fronto-central regions $($ all $\mathrm{p}<0.05)$. There was no significant attribution effect for the situation-attribution in both positive and negative event after post hoc analyses.

Attribution effects were also significant for N2 amplitudes of the situationattribution in positive and negative events and the self-attribution in the negative events (attribution < control trials). P3 latencies showed significant attribution effects for all conditions (attribution < controls), and significant interactions with frontality and laterality indicated that attribution effects were mostly occurred in the central site of parietal regions. Significant interaction effects for P2 and N2 amplitudes did not reveal significant attribution effect after post hoc analyses (attribution $x$ frontality effect on N2 and P3 for the self-attribution and P3 for the situation-attribution in the positive event, attribution $x$ frontality effect on P2 and P3 for the self-attribution and P2 for the situation-attribution in the negative event).

Mean and standard deviation data for P2, N2, P3, LPCs amplitudes and P3 latencies are given in the supplement tables at the very last of this thesis. 


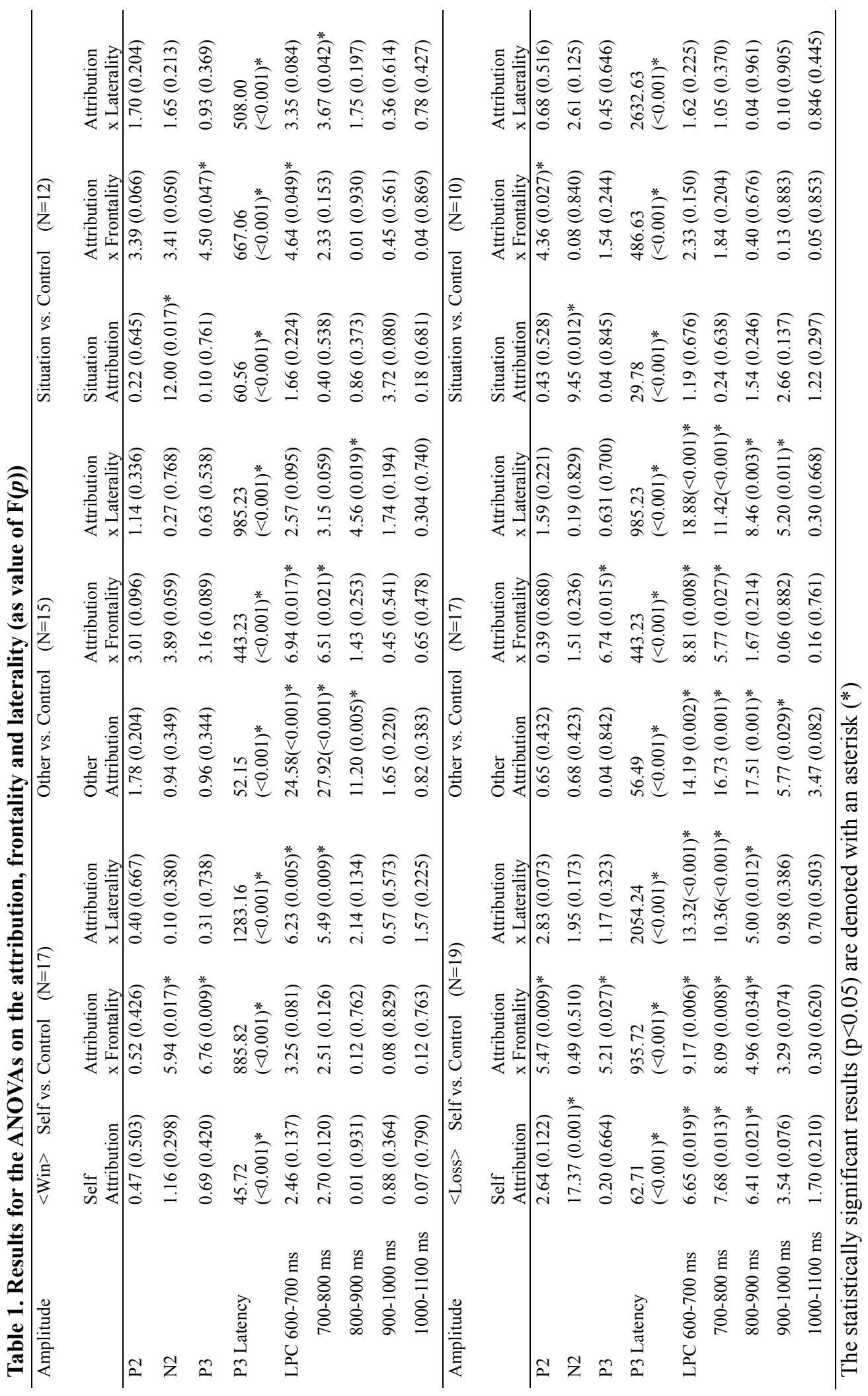



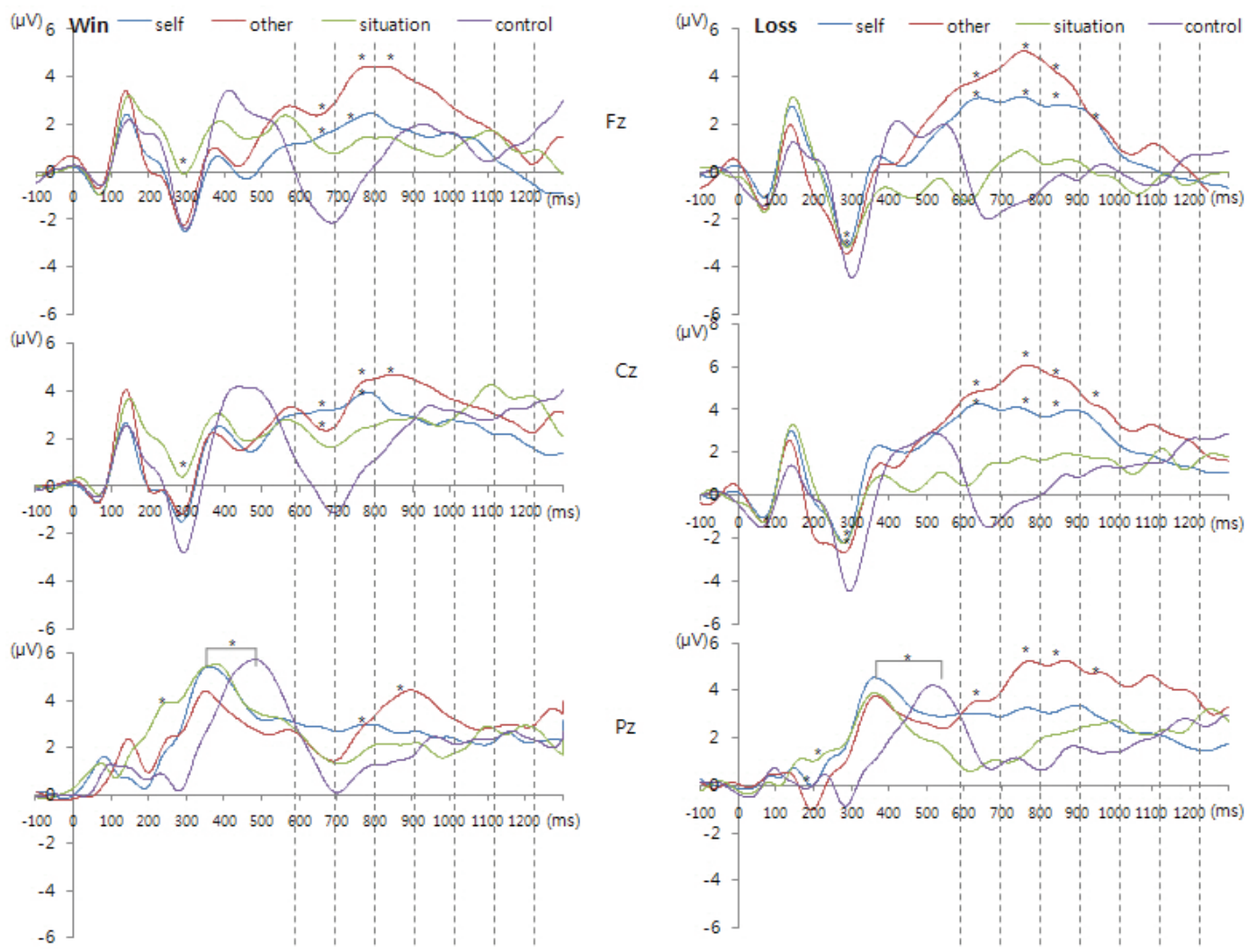

Figure 3. Grand-averaged ERP waveforms at midline channels for self, other, situation attribution trials and control trials in the positive (win) and negative (loss) events. Neural activities which showed significant differences between attribution and control trials were asterisked -N2 amplitudes, P3 latencies, and LPC amplitudes.

Secondly, comparisons of neural activities which showed significant differences between attribution and control trials were done by type of attribution (compare amplitudes of self-other-situation attributions in one event) and by type of event (compare amplitudes of positive-negative events in one attribution).

For comparisons by type of attribution, mean amplitudes of other-attribution were higher than those of self-attribution at the parietal sites regardless of positive and negative events. Mean amplitudes of the other-attribution were higher than those of situation-attribution at almost all electrode sites in both positive and negative events, and the mean amplitudes of the self-attribution were higher than those of situation-attribution for the negative event (Table 2). There was no 
significant difference between attribution types for $\mathrm{N} 2$ amplitudes and P3 latencies.

Table 2. Comparison of neural activities of extracted neural correlates by type of attribution

\begin{tabular}{|c|c|c|c|c|c|c|}
\hline \multirow{2}{*}{$\begin{array}{l}\text { LPC } \\
\text { Time } \\
\text { Window } \\
\text { (ms) }\end{array}$} & \multicolumn{3}{|c|}{ Win } & \multicolumn{3}{|c|}{ Loss } \\
\hline & $\begin{array}{l}\text { Other > } \\
\text { Self } \\
(n=13)\end{array}$ & $\begin{array}{c}\text { Other }> \\
\text { Situation } \\
(n=10)\end{array}$ & $\begin{array}{c}\text { Self }> \\
\text { Situation } \\
(\mathrm{n}=11)\end{array}$ & $\begin{array}{c}\text { Other }> \\
\text { Self } \\
(\mathrm{n}=17)\end{array}$ & $\begin{array}{c}\text { Other }> \\
\text { Situation } \\
(n=9)\end{array}$ & $\begin{array}{c}\text { Self > } \\
\text { Situation } \\
(\mathrm{n}=10)\end{array}$ \\
\hline \multicolumn{7}{|l|}{$600-700$} \\
\hline & n.s & n.s & n.s & n.s & $\mathrm{C} 3, \mathrm{Cz}, \mathrm{C} 4$ & n.s \\
\hline \multirow[t]{3}{*}{$700-800$} & & $\mathrm{~F} 3, \mathrm{~F} 4$, & & & & \\
\hline & n.s & C3,Cz,C4 & n.s & $\mathrm{C} 3$ & $\mathrm{C} 3, \mathrm{Cz}$ & n.s \\
\hline & & & & $\mathrm{P} 3, \mathrm{Pz}$ & $\mathrm{P} 3, \mathrm{Pz}$ & \\
\hline \multirow[t]{3}{*}{$800-900$} & & & & & & F3,Fz,F4 \\
\hline & & $\mathrm{C} 3, \mathrm{Cz}, \mathrm{C} 4$ & n.s & & $\mathrm{C} 3, \mathrm{Cz}, \mathrm{C} 4$ & C3,Cz,C4 \\
\hline & P3, Pz, P4 & $\mathrm{P} 3, \mathrm{Pz}, \mathrm{P} 4$ & & $\mathrm{P} 3, \mathrm{Pz}$ & $\mathrm{Pz}, \mathrm{P} 4$ & $\mathrm{Pz}$ \\
\hline \multirow[t]{3}{*}{$900-1000$} & & & & & & F3,Fz,F4 \\
\hline & & & n.s & & $\mathrm{C} 3, \mathrm{Cz}, \mathrm{C} 4$ & $\mathrm{C} 3, \mathrm{Cz}, \mathrm{C} 4$ \\
\hline & $\mathrm{Pz}$ & P3, Pz, P4 & & $\mathrm{P} 3, \mathrm{Pz}$ & $\mathrm{P} 3, \mathrm{Pz}, \mathrm{P} 4$ & $\mathrm{P} 3, \mathrm{Pz}$ \\
\hline \multirow[t]{2}{*}{$1000-1100$} & & & & & & \\
\hline & n.s & n.s & n.s & n.s & $\mathrm{C} 3, \mathrm{Cz}, \mathrm{C} 4$ & n.s \\
\hline
\end{tabular}

The channels which showed significant difference $(\mathrm{p}<0.05)$ between the attribution conditions by Wilcoxon signed-rank test is indicated.

n.s: There was no significantly different channel between two attribution conditions.

For comparisons by type of event, mean amplitudes of self-attribution in the negative event were significantly higher than those in the positive event for LPC 600-700 ms at $\mathrm{F} 3, \mathrm{Fz}$ and $\mathrm{C} 3, \mathrm{Cz}$ sites $(\mathrm{N}=17$, $\mathrm{p}$ values of Wilcoxon signed-rank test at F3: 0.009, Fz: 0.019, C3: 0.044, Cz: 0.035). There was no significant mean amplitude difference between the positive and negative event for the otherattribution and for the situation-attribution. N2 amplitudes and P3 latencies also showed no significant difference between events. 


\section{DISCUSSION}

This study aimed 1) to extract neural correlates of three types of attribution (self-other-situation) through event-related potentials using a real-time based attribution task and 2) to investigate neural base of self-serving bias through comparison of neural activities of extracted neural correlates by type of attribution and by type of event. We expected that attribution types which contribute to nonself-serving bias (self-attribution for negative events, other/situation-attribution for positive events) would show higher neural activities than attribution types which contribute to self-serving bias (self-attribution for positive events, other/situationattribution for negative events).

\section{Extract neural correlates of attribution}

Neural activities which showed significant differences between attribution trials and control trials were N2 amplitudes, P3 latencies, and late positive complex (LPC) amplitudes. The LPC amplitudes in attribution trials were significantly higher than those in control trials (simple color recognition task) at fronto-central sites and showed moves according to the attribution condition. Therefore, we considered LPCs as neural correlates of attribution in this study. The LPC seemed to be line with frontal late positive potentials which appeared in post-retrieval processing ${ }^{19-21}$. The frontal late positive potentials did not appear in the simple recognition, but appeared in the further evaluation of source or content of memory. Likewise, LPCs in this study did not appear in the simple color recognition (control trials), but appeared in the attribution - a further evaluation of cause of event. The fronto-central LPC was also related with cognitive functions such as hypothesis generation $^{23,24}$ and decision making ${ }^{25}$ in prior studies. Therefore, the LPC in this study seemed to reflect cognitive process of causal attribution for the perceived event. The self and the other attribution showed significantly higher LPC amplitudes than control trials dominantly in the fronto-central sites across the positive and the negative event, but the situation-attribution did not show significant LPCs. One possible explanation for this finding was that the construct of attribution was basically consisted of self and other attribution, and the situation-attribution 
might be another process such as a 'putting-down' process ${ }^{18}$ rather than an actual 'attribution'. Another explanation was that the construct of the colour test was not suitable to realize the situation-attribution because this task required participants to appraise the result of person's performance.

A prior study which examined neural correlates of attribution using ERPs demonstrated the amplitude difference between attribution conditions at the $320 \mathrm{~ms}$ peak $^{17}$. However, P300 amplitudes in this study did not show significant difference between attribution and control trials, neither did between attribution conditions. This result difference might be due to a difference of variables. A previous study ${ }^{17}$ compared neural activities of attribution using composite variables (i.e. self-serving attribution (a summation of self-attribution in the positive event and situationattribution in the negative event) vs. non-self-serving attribution (a vice versa)), and did not include the other-attribution. However, P300 amplitudes of each attribution (self-other-situation) were examined in this study. P300 has been known to reflect attentional process, and the load of attention might be different between the selfserving and the non-self-serving attribution such as in prior study, but it might not be too different to make significant difference between each attribution condition.

P3 latencies were shorter in attribution trials than in control trials regardless of type of attribution or event. P3 latency differences might be due to a difference of trial frequency or task content between attribution and control trials. Smaller N2 amplitudes in the situation-attribution might reflect lower cognitive demand of situation-attribution, or other cognitive process such as putting down.

Above results suggested that the 'colour test' which was newly developed as a real-time based attribution task in this study might be an effective tool to examine the mechanism of attribution. The strength of the colour test was that it enabled to investigate the attribution in real-time and in three types of attribution (self-othersituation) respectively using an online game format.

\section{Comparison of extracted neural correlates by type of attribution}

In the comparison between the self and the other attribution, LPC amplitudes of other-attribution were significantly higher than those of self-attribution at the 
parietal sites regardless of the positive and negative event. The expected interaction effect based on self-serving bias, that was higher amplitudes of other-attribution in the positive event and the higher amplitudes of self-attribution in the negative event, was not observed. It might be suggested that even if a person more attribute to others for negative events in behavioral level, other-attribution might demand more recruit of cognitive resources in the brain level. A previous study ${ }^{18}$ showed that the attribution of fluent stimuli to alternative sources evoked higher LPC activity than that to past experience. They suggested that the late positive potential was involved in rejecting brain "default" mode and attributing the source to new one or alternatives. Likewise, we supposed that the attribution to self might be more usual and "default" processing, whereas the attribution to others was a secondary or more demanding process to protect self-esteem. However, this supposition for the default mode of self-attribution might not be universal one. Participants of this study did not show self-serving bias in the behavioral level, and the self-attribution was their most frequent attribution style in both positive and negative events. Therefore, default mode of causal attribution might be different according to participants' social or cultural backgrounds. Further studies with other populations with various backgrounds would be helpful to clarify this question.

\section{Comparison of extracted neural correlates by type of event}

In the comparison between the positive and the negative event, LPC amplitudes of self-attribution in the negative event were significantly higher than those in the positive event at the fronto-central sites (F3, Fz, C3, Cz). This finding was consistent with previous findings that non-self-serving attribution generated higher neural activities than self-serving attribution did. There was no significant LPC amplitudes difference between the positive and the negative event for the other-attribution and the situation-attribution. This finding suggested that the selfattribution might play a key role in the attribution process which determined the direction of attribution such as a self-serving. 


\section{Limitations}

Some findings from present study should be interpreted carefully. First, selfserving bias was not revealed in the behavioral data. Attribution style was known to be very varied across persons, and there were other previous findings that selfserving bias did not reveal in Korean subjects ${ }^{26,27}$. Previous researchers suggested that the virtue of modesty which was emphasized in the Eastern culture might suppress the appearance of self-serving tendency ${ }^{26,27}$. The attribution could be also influenced by self-confidence for their accuracy. Relationship between behavioral variables and the w-VAS scale which measures subjective confidence for correctness was examined, but there was no significant correlation $(\mathrm{p}>0.325)$. To examine the internal construct of the colour test, correlation analyses with scores of attribution scale (ASCQ) were done and the consistency between two attribution measures revealed in considerable dimensions. Second, the permitted limit of number of trials $(n=15)$ was relatively smaller than usual limit $(n=20)$ in ERP studies. However, the mean amplitude method which was used to analyze the LPCs was known to be favorable to reduce contamination effect of noises, and also preferable when the included number of trials was different in each condition ${ }^{28}$. On the other hand, the results of P2, N2, P3 which were identified by baseline-to-peak method need to be interpreted more tentatively. Third, subjects entered into the analyses were different in each comparison because not all subjects responded over 15 times across all six kinds of attribution. If we included subjects who showed acceptable response numbers for all six attributions, a substantial portion of subjects would be neglected. Rather, we decided to compare each attribution over 15 responses with control trials respectively. Because multiple comparisons could increase the type I error, we performed only hypothesis-based comparisons. 


\section{CONCLUSION}

Taken together present findings, 1) the fronto-central late positive complex (LPC) was extracted as a neural correlate of attribution, 2) higher LPC amplitudes of other-attribution than those of self-attribution suggested that the other-attribution might demand more cognitive loads than self-attribution, and 3) higher LPC amplitudes of self-attribution for the negative event than those for the positive event suggested that the self-attribution might play a pivotal role in determining attribution style such as self-serving bias. As we know, this was the first study that demonstrated neural correlates of each attribution respectively. Applying this realtime based paradigm to clinical population such as depression or paranoia patients would provide further insights for the role of attribution in human psychopathologies. 


\section{REFERENCES}

1. Green MF, Penn DL, Bentall R, Carpenter WT, Gaebel W, Gur RC, et al. Social cognition in schizophrenia: an NIMH workshop on definitions, assessment, and research opportunities. Schizophr Bull 2008;34:1211-20.

2. Bellack AS, Green MF, Cook JA, Fenton W, Harvey PD, Heaton RK, et al. Assessment of community functioning in people with schizophrenia and other severe mental illnesses: a white paper based on an NIMH-sponsored workshop. Schizophr Bull 2007;33:805-22.

3. Velthorst E, Nieman DH, Linszen D, Becker H, de Haan L, Dingemans PM, et al. Disability in people clinically at high risk of psychosis. Br J of Psychiatry 2010;197:278-84.

4. Montreuil T, Bodnar M, Bertrand M, Malla AK, Joober R, Lepage M. Social cognitive markers of short-term clinical outcome in first-episode psychosis. Clin Schizophr Relat Psychoses 2010;4:105-14.

5. Couture SM, Penn DL, Roberts DL. The functional significance of social cognition in schizophrenia: a review. Schizophr Bull 2006 Oct;32 Suppl 1:44- 63 .

6. Bentall RP, Corcoran R, Howard R, Blackwood N, Kinderman P. Persecutory delusions: a review and theoretical integration. Clin Psychol Rev 2001;21:1143-92.

7. Langdon R, Corner T, McLaren J, Ward PB, Coltheart M. Externalizing and personalizing biases in persecutory delusions: the relationship with poor insight and theory-of-mind. Behav Res Ther 2006;44:699-713.

8. Candido CL, Romney DM. Attributional style in paranoid vs. depressed patients. Br J Med Psychol 1990;63:355-63.

9. Kinderman P, Bentall R. A new measure of causal locus: the internal, personal and situational attributions questionnaire. Pers Individ Dif 1996;20:261-4.

10. Kaney S, Bentall RP. Persecutory delusions and the self-serving bias. Evidence from a contingency judgment task. J Nerv Ment Dis 1992 Dec;180:773-80. 
11. Tennen H, Herzberger S. Depression, self-esteem, and the absence of selfprotective attributional biases. J Pers Soc Psychol 1987;52:72-80.

12. Kaney S, Bentall RP. Persecutory delusions and attributional style. Br J Med Psychol 1989;62:191-8.

13. Aakre JM, Seghers JP, St-Hilaire A, Docherty N. Attributional style in delusional patients: a comparison of remitted paranoid, remitted nonparanoid, and current paranoid patients with nonpsychiatric controls. Schizophr Bull 2009;35:994-1002.

14. Peterson C, Villanova P. An Expanded Attributional Style Questionnaire. J Abnorm Psychol 1988;97:87-9.

15. An SK, Kang JI, Park JY, Kim KR, Lee SY, Lee E. Attribution bias in ultra-high risk for psychosis and first-episode schizophrenia. Schizophr Res 2010 May;118:54-61.

16. Blackwood NJ, Bentall RP, ffytche DH, Simmons A, Murray RM, Howard RJ. Self-responsibility and the self-serving bias: an fMRI investigation of causal attributions. Neuroimage 2003;20:1076-85.

17. Krusemark EA, Keith Campbell W, Clementz BA. Attributions, deception, and event related potentials: an investigation of the self-serving bias. Psychophysiology $2008 \mathrm{Jul} ; 45: 511-5$.

18. Bentall RP. Social cognition and delusional beliefs. In: Corrigan PW, Penn, DL, editor. Social cognition and schizophrenia. Washington, DC: American Psychological Association; 2001. p. 123-48.

19. Wolk DA, Schacter DL, Berman AR, Holcomb PJ, Daffner KR, Budson AE. An electrophysiological investigation of the relationship between conceptual fluency and familiarity. Neurosci Lett 2004 Oct 14;369:150-5.

20. Goldmann RE, Sullivan AL, Droller DB, Rugg MD, Curran T, Holcomb PJ, et al. Late frontal brain potentials distinguish true and false recognition. Neuroreport 2003 Sep 15;14:1717-20.

21. Ranganath C, Paller KA. Neural correlates of memory retrieval and evaluation. Brain Res Cogn Brain Res 2000 Mar;9:209-22. 
22. Lee H. An Exploratory Study on the Cause of Paranoia: The Self-Concept and Reasoning Bias. Kor J of Clin Psychol 1999;18:1-15.

23. Li F, Cao B, Lei Y, Li H. Electrophysiological correlates of hypothesis testing. Neuroreport 2009 Jan 28;20:197-201.

24. Li F, Cao B, Gao X, Xiao F, Qing J, Li H. Temporal course and the electrophysiological correlates of hypothesis testing as revealed in a modified category induction task. Brain Res 2009 Dec 8;1301:61-7.

25. Ruchkin DS, Munson R, Sutton S. P300 and slow wave in a message consisting of two events. Psychophysiology 1982 Nov;19:629-42.

26. Park S, Shin, M., Lee, H. Explicit and indirect attributional styles of over and covert narcissists. Kor J of Clin Psychol 2005;24:465-74.

27. Lee H, Won, H. The Self-Concepts, the Other-Concepts, and Attributional Styles in Paranoia and Depression. Kor J of Clin Psychol 1998;17:105-25.

28. Talsma D, Woldorff, MG. Methods for the Estimation and Removal of artifacts and Overlap in ERP Waveforms In: Handy TC, editor. Even-Related Potentials; A Menthos Handbook. Cambridge: The MIT press; 2004. p. 114-48. 


\title{
$<$ ABSTRACT (IN KOREAN) $>$
}

\section{실시간 귀인과제를 이용한 귀인의 사건유발 전위}

\author{
〈지도교수: 안석균 교수>
}

연세대학교 대학원 의학과

$$
\text { 이 수 영 }
$$

귀인(attribution)은 우울이나 피해 망상과 같은 주요 정신과적 증상의 발생기전을 설명하는 사회인지 기능이다. 본 연구의 목적은 자기귀인, 타인귀인, 상황귀인 각각에 대한 신경 연관물을 추출하고, 각 귀인 간에 추출된 신경연관물의 활성도를 비교하여 자기귀인 편향의 신경기초를 규명하는 것이다. 본 연구를 위하여 실제와 같은 상황에서 세 가지 종류의 귀인을 할 수 있는 색깔 검사 (colour test)를 개발하였다. 정상 성인 20 명을 대상으로 하였으며, 각각의 참가자에게는 온라인으로 접속된 다른 두 명의 참가자와 함께 색깔 맞추기 게임을 하게 된다고 설명하였다. 뇌파를 통해 사건 유발 전위를 측정하면서 게임의 승패에 대한 원인을 자기, 타인, 또는 상황에 귀인 하도록 지시 하였다. 연구 결과, 주로 전두엽과 중앙 채널에서 두드러지는 후기 양성 전위(late positive complex)를 귀인의 신경연관물로 추출하였다. 긍정 사건과 부정 사건 내에서 자기, 타인, 상황 귀인 시 후기 양성 전위의 진폭을 비교한 결과, 긍정 사건과 부정 사건 모두에서 자기 귀인 시 보다 타인 귀인 시에 
더 큰 진폭의 후기 양성 전위가 나타났다. 이는 자기 귀인 시 보다 타인 귀인 시에 더 큰 인지적 부담 (cognitive demand)이 부여됨을 반영하는 것으로 생각된다. 다음으로 한 가지 귀인 내에서 긍정 사건과 부정 사건 간의 진폭을 비교를 하였을 때에는, 긍정 사건을 자기 귀인 할 때 보다 부정 사건을 자기 귀인 할 때 더 큰 후기 양성 전위의 진폭이 나타났다. 이는 자기 귀인 편향 (self-serving bias) 이론에 부합되는 결과로, 자기에 대한 귀인이 자기 귀인 편향의 신경 생리학적 기초가 될 수 있음을 시사한다. 본 실시간 귀인 검사로 개발된 색깔 검사를 우울증이나 편집증과 같은 임상 환자군에 적용한다면 인간의 정신병리에서 귀인의 작용 기전에 대한 보다 심도 있는 통찰이 가능할 것으로 기대된다.

핵심 되는 말: 귀인, 자기 보존 편향, 컬러테스트, 사건 유발 전위, 사회 인지 


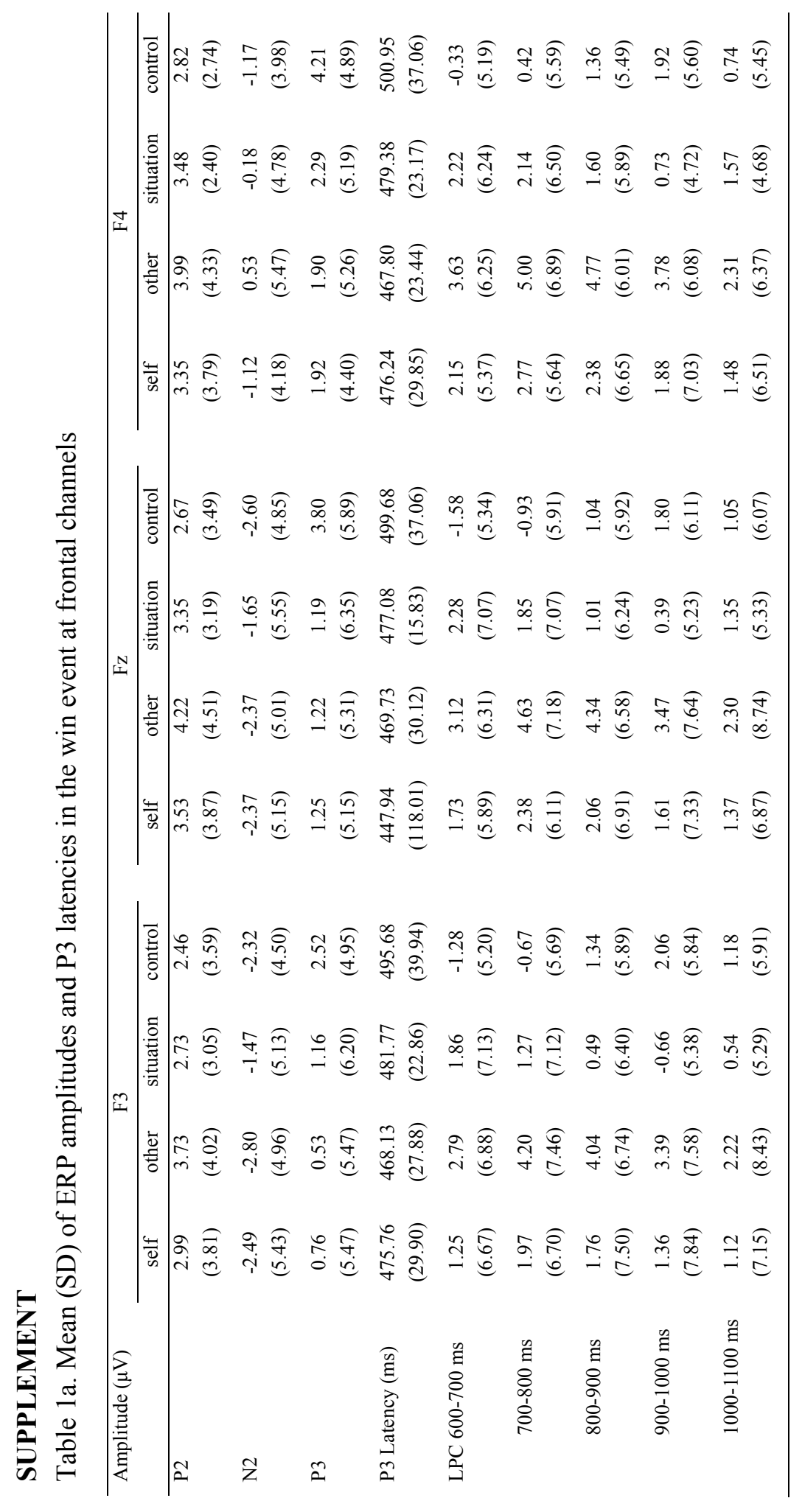




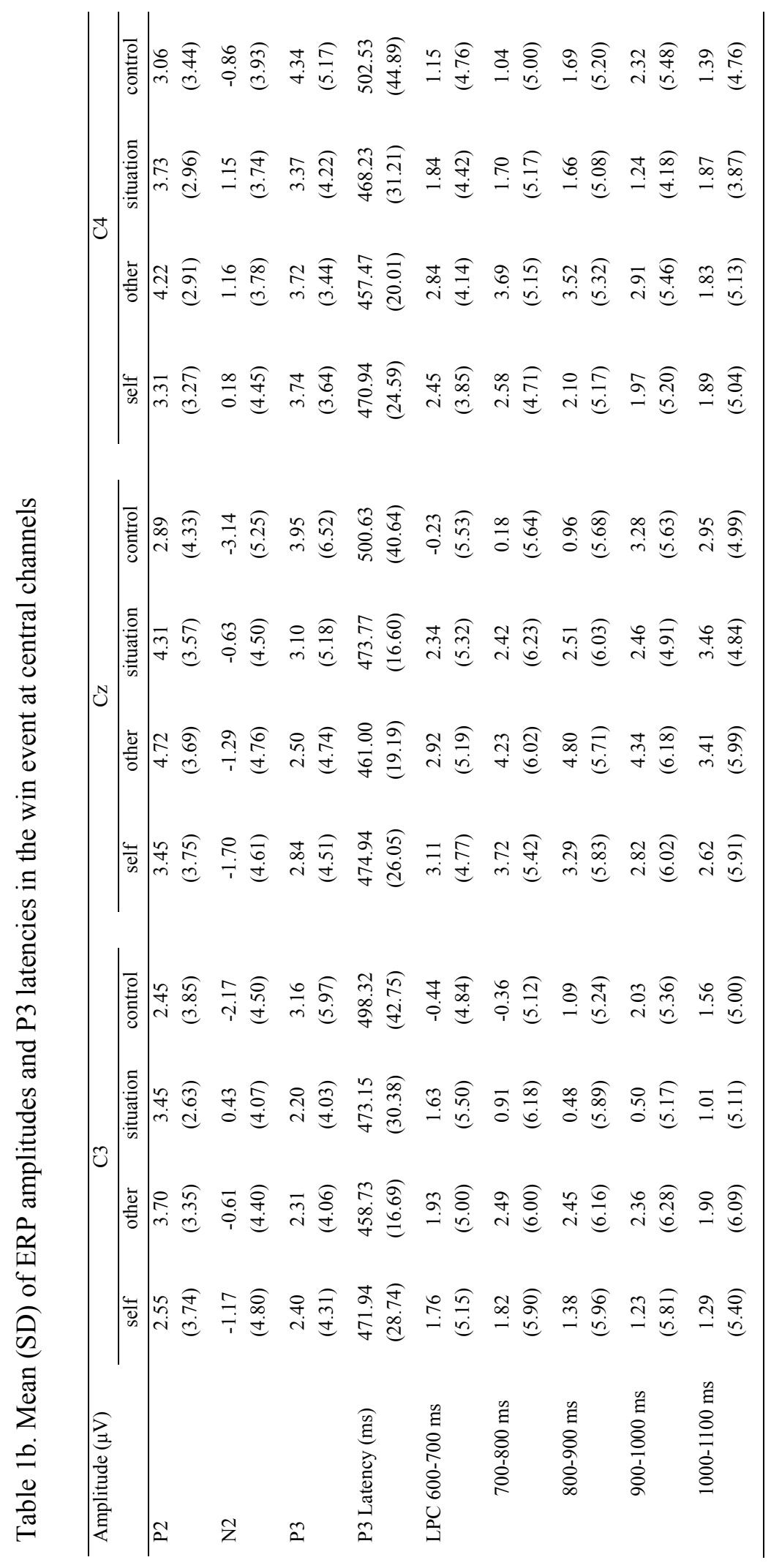




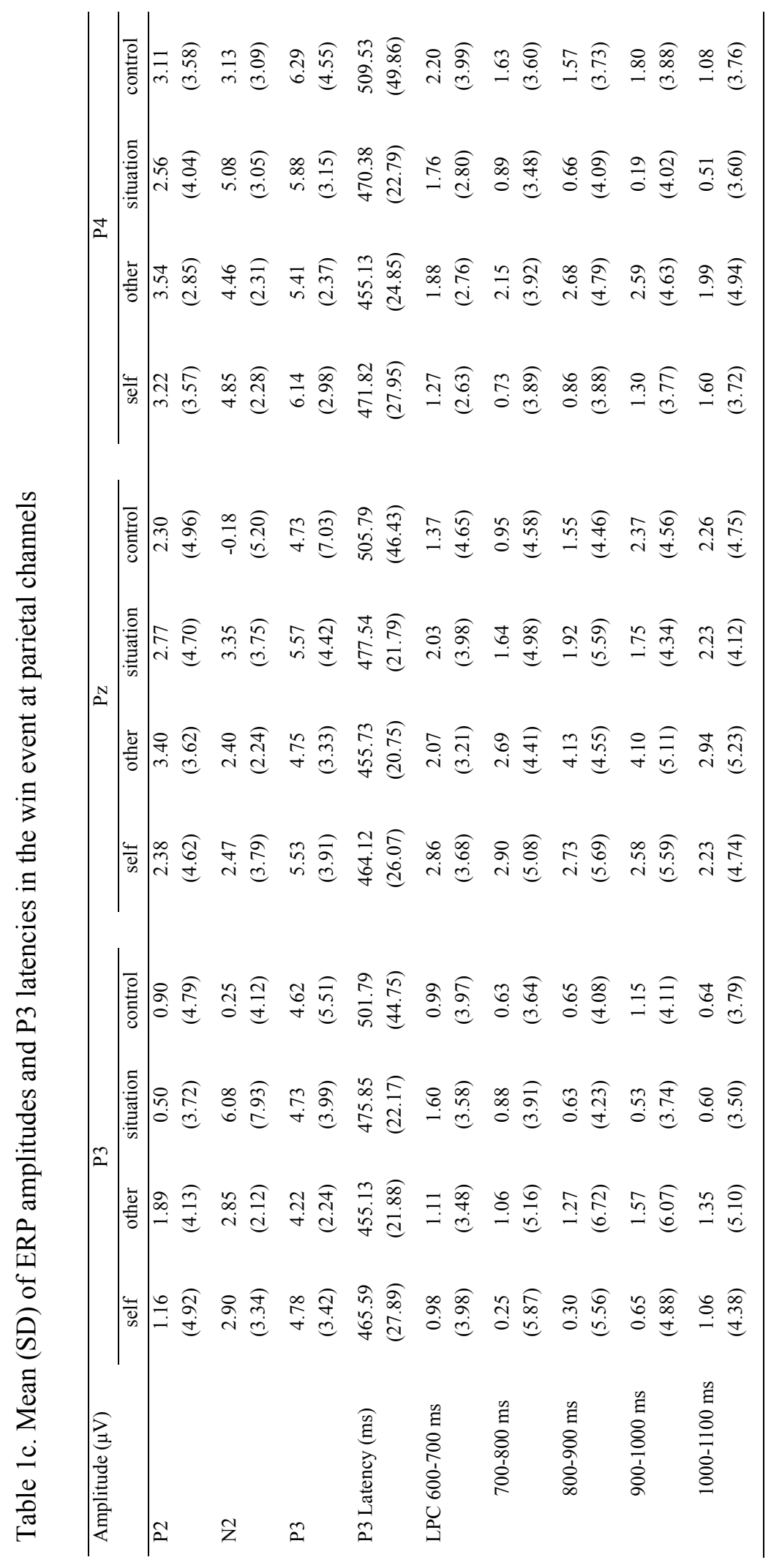




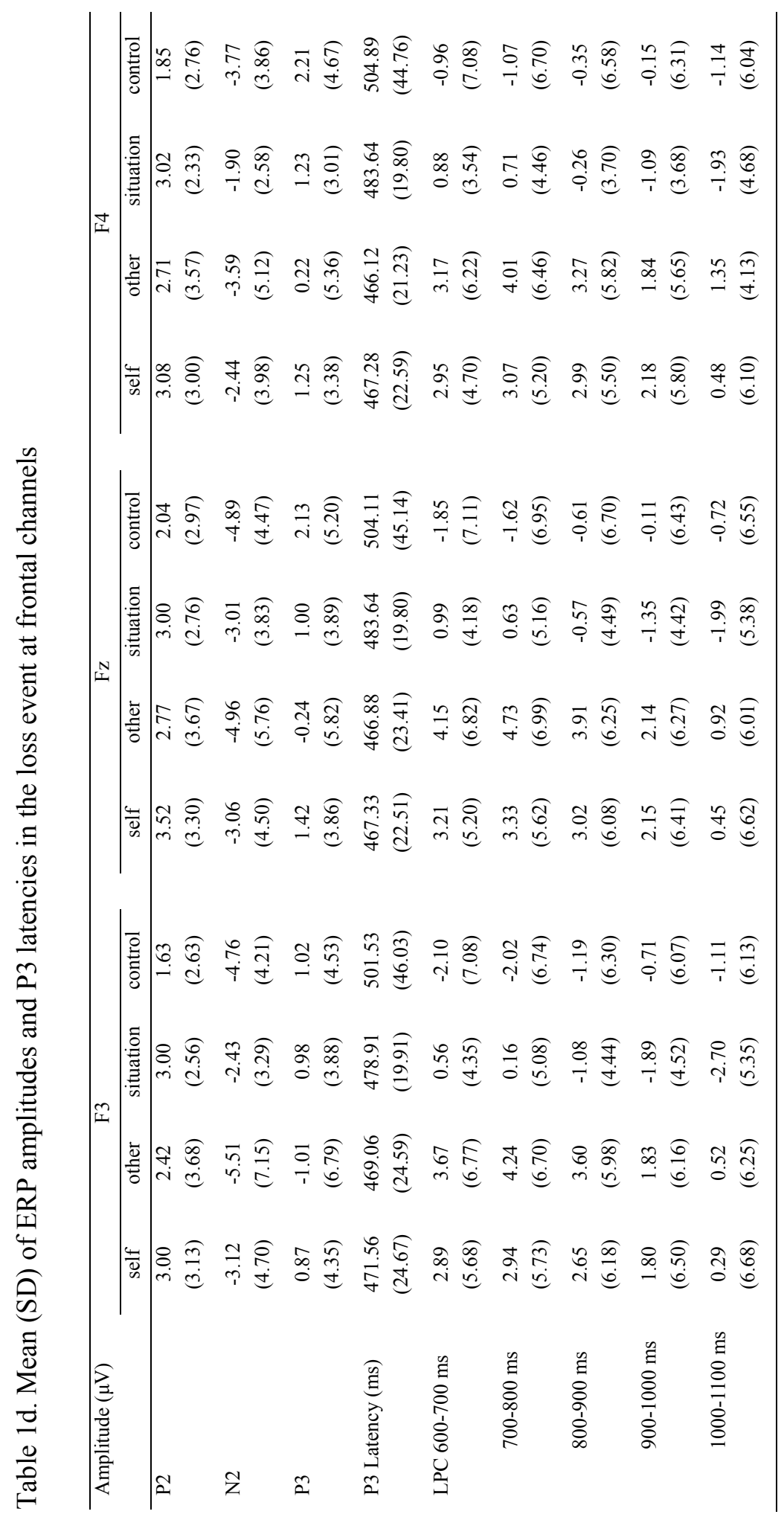




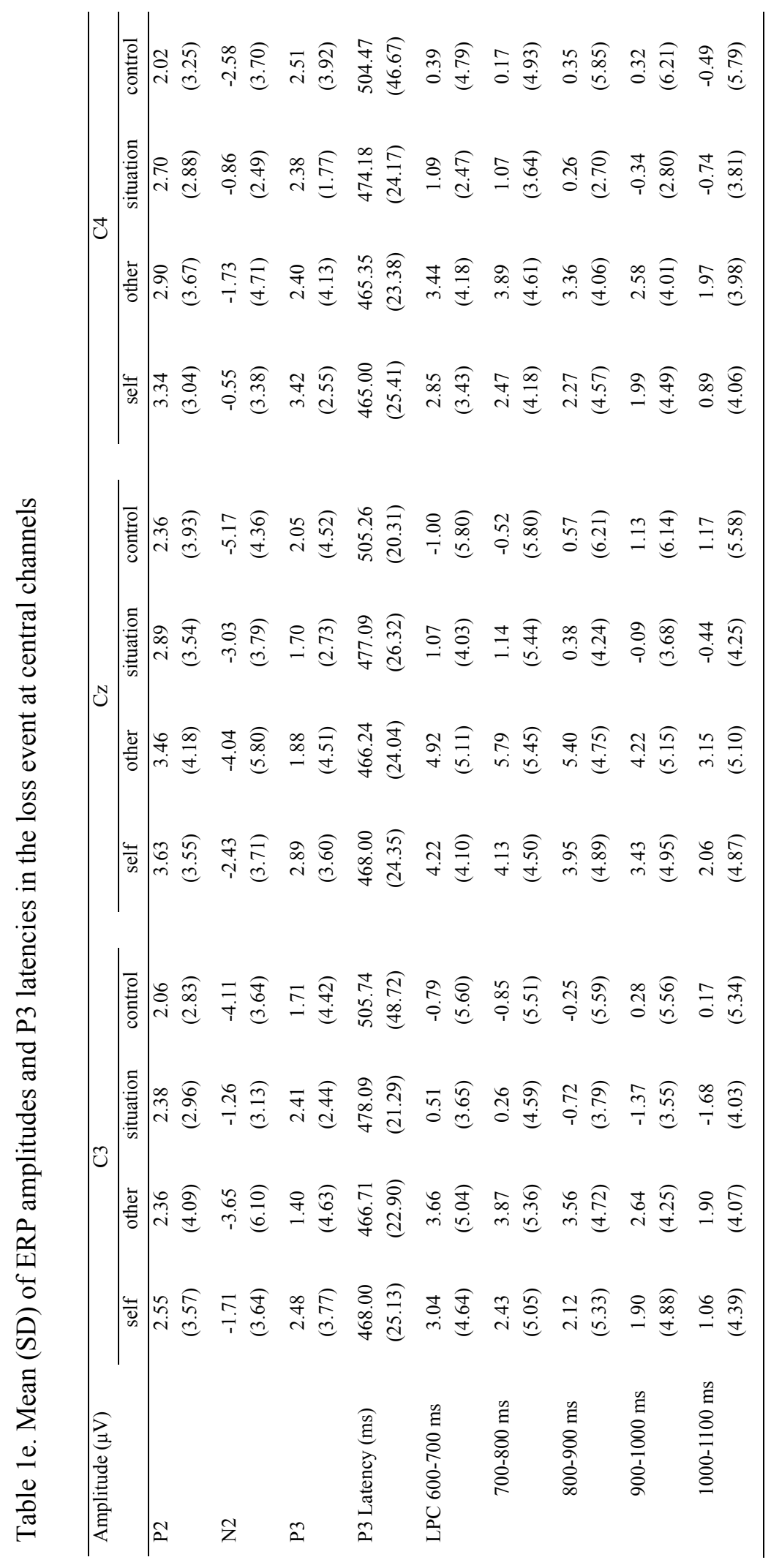




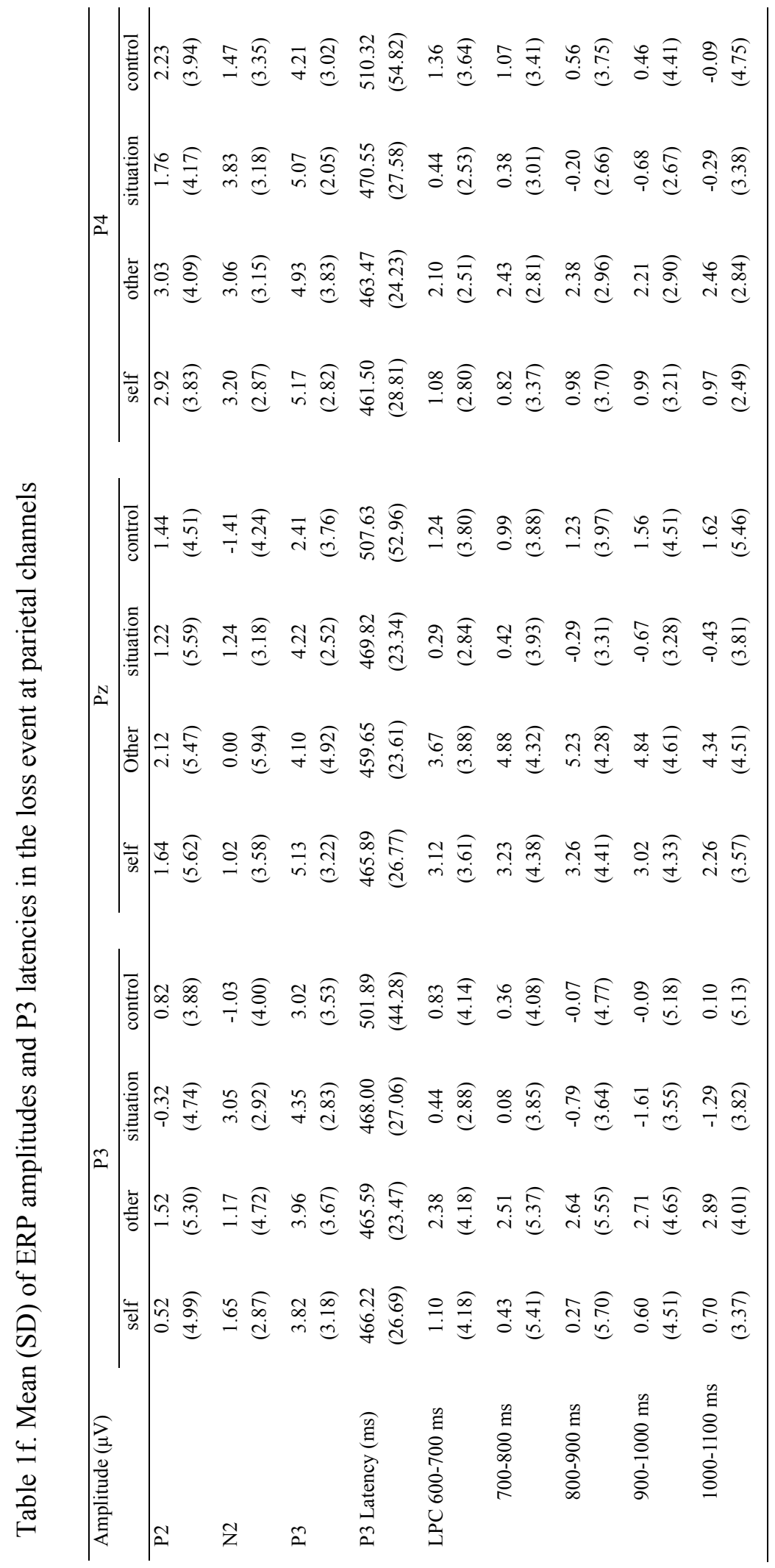

